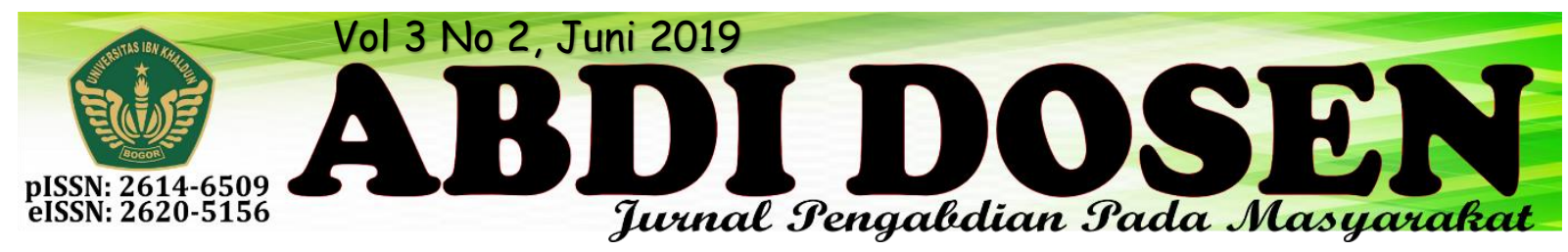

\title{
MENINGKATKAN KUALITAS REMAJA KAMPUNG PONCOL CIAMPEA DENGAN DI BENTUKNYA REMAJA MESJID
}

\author{
Ahmad Sobari $^{1}$, Muhamad Fikri, Rita Otaviani ${ }^{2}$ \\ ahmadsobari@fai.uika-bogor.ac.id ${ }^{1}$ \\ mf130496@gmail.com $^{2}$ \\ Fakultas Agama Islam Universitas Ibn Khaldun', Mahasiswa KKN Kelompok 11 Tahun $2018^{2}$
}

\begin{abstract}
ABSTRAK
Pemuda adalah individu yang bila dilihat secara fisik sedang mengalami perkembangan dan secara psikis sedang mengalami perkembangan emosional, sehingga pemuda merupakan sumber daya manusia pembangunan baik saat ini maupun masa datang. Sebagai calon generasi penerus yang akan menggantikan generasi sebelumnya maka di perlukan para pemuda atau remaja yang baik agama dan akhlaknya. Pemuda yang agamis akan menjadikan suatu wilayah atau kampung menjadi lebih hidup dalam berbagai aspek salah satunya yaitu dalam pendidikan keagamaan.Pengabdian kepada masyarakat merupakan salah satu Tri Darma perguruan tinggi yang mutlak harus direalisasikan oleh setiap mahasiswa baik dalam kelompok maupun individu. Mahasiswa di tempatkan ke daerah-daerah untuk bisa hidup bermasyarakat, mengaplikasikan ilmu yang di dapat selama di kampus dalam rangka mengembangkan potensi masyarakat dari daerah tersebut. Lokasi yang dituju berada di Kp. Poncol RT 5 RW 03 Desa Ciampea Kecamatan Ciampea Kabupaten Bogor. Berdasarkan informasi dari kepala desa Ciampea bahwasanya para remaja di Desa Ciampea sudah terkenal akan kenakalannya, mabuk, narkoba, serta tauran sudah menjadi hal yang biasa. Kurangnya pengetahuan mengenai keagamaan yang menjadi penyebab kenakalan remaja terjadi ditambah dengan kurangnya perhatian para orang tua untuk mengarahkan kepada anak-anaknya mengenai pemahaman agama di karenakan beberapa orang tua di Desa Ciampea juga kurang dalam memahami ilmu agama.
\end{abstract}

Kata kunci: KKN, Pengabdian Masyarakat

\section{PENDAHULUAN}

\section{Latar Belakang}

Tujuan utama KKN ini adalah menempatkan mahasiswa diluar kampus agar mahasiswa hidup ditengah-tengah masyarakat bersama masyarakat untuk membantu dan mendampingi masyarakat manfaatkan potensi sumber daya alam lokal dan sumber daya manusia yang ada untuk mengatasi permasalahan masyarakat dalam kurun waktu tertentu. KKN Tematik Terintegrasi Universitas Ibnukhaldun
Bogor merupakan kewajiban bagi mahasiswa semester VI ke atas. KKN Tematik Terintegrasi Universitas Ibnukhaldun Bogor bagi masyarakat yakni untuk meningkatkan kesadaran masyarakat dengan berperan aktif dalam membangun produktifitas suber daya pembangunan sesuai dengan fasilitas yang dimiliki.

Lembaga penelitian dan pengabdian masyarakat Universitas Ibnukhaldun Bogor telah melaksanakan KKN pada tahun 2007, 
KKN Terintegrasi pada tahun 2015 di Kabupaten Bogor KKN Tematik Jawa Barat pada tahun 2012 di kota Depok KKN Tematik POSDAYA pada tahun 2013 di Kabupaten Bogor, dan KKN Tematik Jawa Barat pada tahun 2013 di Kota Depok, KKN Tematik Jawa Barat, dan KKN Tematik POSDAYA TAHUN 2014 dan 2015 di Kecamatan Caringin , Cigombong, Cijeruk dan Kecamatan Taman sari Kabupaten Bogor.

Kegiatan KKN Tematik Terintegrasi Universitas Ibnukhaldun Bogor tahun 2018 merupakan salah satu kegiatasn dengan pendekatan comunity devlopment, dimana pada pelaksanaan kegiatan ini melakukan proses perencanaan sekaligus aksi program pendampingan masyarakat baik pada asoek sosia, ekonomi, kesehatan, pendidikan, hukum, dan agama maupun teknologi tepat guna secara terpadu.

Kecamatan Ciampea mempunyai luas wilayah $\pm 3.297,91$ hektar. Dan memiliki Batas wilayah Kecamatan tersebut yaitu, sebelah utara adalah Kecamatan Rancabungur, sebelah abarat adalah Kecamatan Cibungbulang, sebelah sekatan

\section{METODE PENGABDIAN}

Metode yang digunakan dalam program KKN ini terbagi atas 3 tahap, yaitu persiapan, cara kerja atau tahapan pekerjaan, pelaksanaan kegiatan dan evaluasi.

\section{a. Persiapan}

Persiapan untuk menyusun PROGRAM KKN yaitu survei lokasi, penyuluhan, kordinasi dengan kepala desa , sosialisasi RT/RW.

Untuk mensukseskan KKN Tematik Terintegrasi Universitas Ibn Khaldun Bogor Tahun akademik 2017-2018 diharapakan semua elemen dalam hal ini baik mahasiswa, masyarakat dan para tokoh-tokoh desa saling bersinergi satu sama lain demi adalah Kecamatan Tenjolaya dan Kecamatan Pamijahan, sebelah timur adalah Kecamatan dramaga. Kecamatan tersebut terdiri dari 13 desa di antaranya, desa ciampea udik, desa cinangka, desa cibuntu, desa cicadas, desa tegal waru, desa bojong jengkol, desa cihideng udik, desa cihideng ilir, desa cibanteng, desa bojong rangkas, desa cibadak, desa benteng, desa ciampea. Pada tahun 2014 jumlah penduduk kecamatan ciampea 156.070 yang di bagi menjadi 80.231 laki-laki dan 75.839 wanita.

Sementara itu Desa Ciampea memiliki luas wilayah 246 hektar dan memiliki jumlah penduduk sebanyak 11.373 penduduk. Batas wilayah Desa Ciampea untuk bagian Utara yaitu Desa Cisadane, sebelah selatan yaitu Bojong Rangkas, sebelah sebelah selatan yaitu Desa Kali Cikarang dan sebelah timur yaitu Desa Benteng.

Kampung Poncol berada di RT 05 RW 03 Desa Ciampea kecamatan Ciampea kabupaten Bogor. Kampung Poncol memiliki jumlah penduduk kurang lebih 700 jiwa yang terdiri dari 140 Kartu keluarga.

mensukseskan semua kegiatan-kegiatan yang telah di susun bersama dengan keolompok KKN.

\section{b. Pelaksanaan Program KKN UIKA KELOMPOK 11}

Kelompok KKN UIKA dari berbagai fakutas dan disatukan menjadi satu kelompok di antaranya: Fakultas Teknik, Fakultas Ekonimi, Fakultas Agama Islam, Fakultas Ilmu Kesehatan, Fakultas Keguruan dan Ilmu Pendidikan. Masing-masing fakultas anggota kelompok 11 KKN Terintegrasi UIKA Bogor memiliki program kerja unggulan. 
Meskipun begitu program kerja dikerjakan

bersama dengan seluruh anggota kelompok.

\begin{tabular}{|c|c|c|c|c|c|c|c|c|c|c|c|c|c|c|c|c|c|c|c|c|c|c|c|c|c|c|c|c|c|c|}
\hline \multirow{2}{*}{ NO } & \multirow{2}{*}{ JADWAL KEGIATAN } & \multicolumn{29}{|c|}{7 AGUSTUS - 5 SEPTEMBER 2018} \\
\hline & & 7 & 8 & 9 & 10 & 111 & 121 & $13 \mid 1$ & 41 & \begin{tabular}{|l|l|}
5 & 16 \\
\end{tabular} & 17 & 18 & 19 & 20 & 212 & 22 & 23 & 242 & 25 & 6 & 272 & 28 & 293 & 303 & 11 & 1 & 2 & 3 & 4 & 5 \\
\hline 1 & Penerimaan KKN & & & & & & & & & & & & & & & & & & & & & & & & & & & & & \\
\hline 2 & Observasi & & & & & & & & & & & & & & & & & & & & & & & & & & & & & \\
\hline 3 & Rapat Pemuda & & & & & & & & & & & & & & & & & & & & & & & & & & & & & \\
\hline 4 & Acara Kemerdekaan & & & & & & & & & & & & & & & & & & & & & & & & & & & & & \\
\hline 5 & Pengajian Warga & & & & & & & & & & & & & & & & & & & & & & & & & & & & & \\
\hline 6 & Mengajar di MI & & & & & & & & & & & & & & & & & & & & & & & & & & & & & \\
\hline 7 & Mengajar Al Qur'an & & & & & & & & & & & & & & & & & & & & & & & & & & & & & \\
\hline 8 & Les Bahasa Inggris & & & & & & & & & & & & & & & & & & & & & & & & & & & & & \\
\hline 9 & Les Komputer & & & & & & & & & & & & & & & & & & & & & & & & & & & & & \\
\hline 10 & Kunjungan Ke Desa & & & & & & & & & & & & & & & & & & & & & & & & & & & & & \\
\hline 11 & Penampungan Air & & & & & & & & & & & & & & & & & & & & & & & & & & & & & \\
\hline 12 & Kesehatan Gratis & & & & & & & & & & & & & & & & & & & & & & & & & & & & & \\
\hline 13 & UMKM & & & & & & & & & & & & & & & & & & & & & & & & & & & & & \\
\hline 14 & Remaja Mesjid & & & & & & & & & & & & & & & & & & & & & & & & & & & & & \\
\hline 15 & Celengan Kardus & & & & & & & & & & & & & & & & & & & & & & & & & & & & & \\
\hline 16 & Perpisahan & & & & & & & & & & & & & & & & & & & & & & & & & & & & & \\
\hline 17 & Pulang & & & & & & & & & & & & & & & & & & & & & & & & & & & & & \\
\hline 18 & Pelepasan KKN & & & & & & & & & & & & & & & & & & & & & & & & & & & & & \\
\hline
\end{tabular}

\section{HASIL}

\section{Bidang Agama Islam}

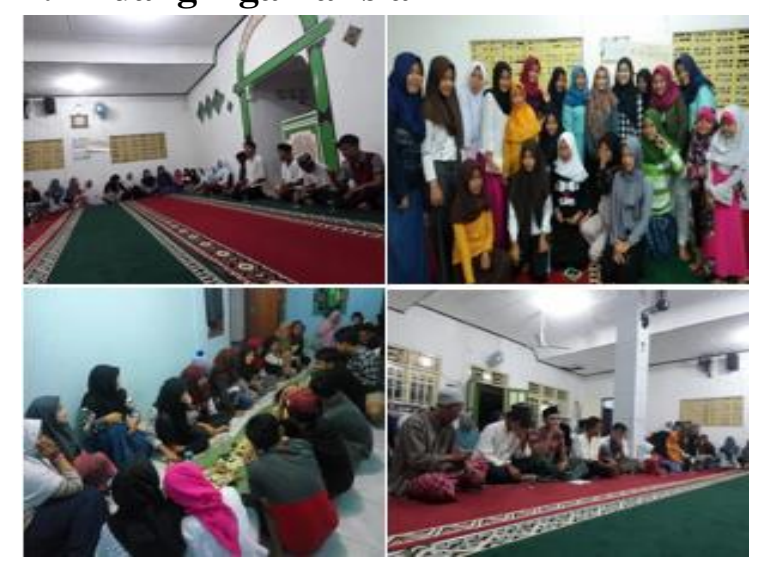

Pembuatan remaja mesjid di kp.poncol kecamatan ciampea ini melakukan aktivitas sosial dan pengajian pada setiap malam jum'at dilingkungan mesjid dan masyarakat sekitarnya.para remaja yang ikut dalam kegiatan-kegiatan yang ada didalam masjid maupun sekitarnya secara tidal langsung ikut berpartisipasi dalam meramaikan masjid dan juga membantu dalam berbagai hal yang berkaitan dengan kegiatan dimasjid. Diantara perjuangan di jalan Allah adalah aktivitas memakmurkan masjid. Dan hendaklah ada diantara kamu segolongan umat yang menyeru kebajikan.

Remaja masjid merupakan salah satu bentuk organisasi da'wah islamiyah seperti memperingati isra miraj untuk mengorganisir kegiatan memakmurkan masjid yang dilakukan para remaja muslim yang memiliki komitmen da'wah dan adanya pengajian setiap malam jum'at, remaja masjid sangat diperlukan sebagai alat untuk mencapai tujuan da'wah dan pengajian pada remaja masjid adalah wadah bagi remaja muslim dalam beraktivitas dimasjid. 


\section{Bidang Pendidikan}

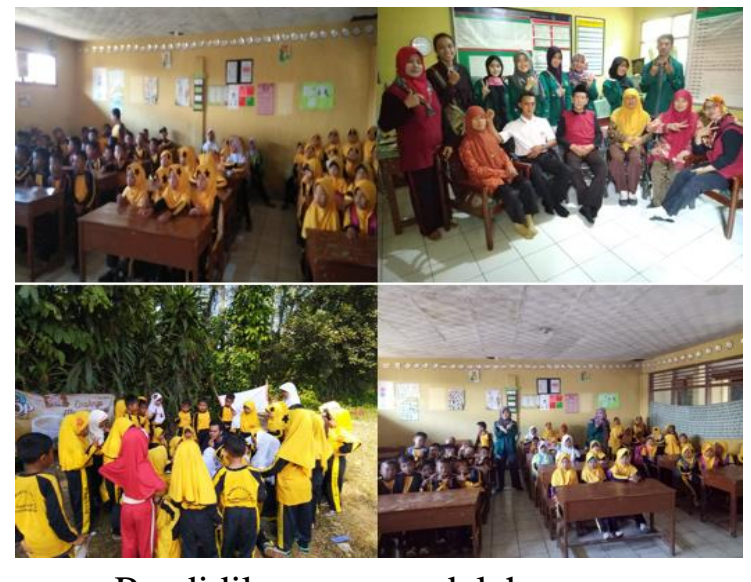

Pendidikan

adalah

upaya

mengembangkan

potensi-potensi

manusiawi peserta didik baik potensi fisik potensi cipta, rasa, maupun karsanya, agar potensi itu menjadi nyata dan dapat berfungsi dalam perjalanan hidupnya sebagai individu dan masyarakat. Dasar pendidikan adalah cita-cita kemanusiaan universal. Pendidikan bertujuan menyiapkan pribadi dalam keseimbangan, kesatuan. organis, harmonis, dinamis. guna mencapai tujuan hidup kemanusiaan.

Dalam kegiatan Mengajar di Manba'ul ulum 2 kp.poncol kecamatan ciampea sudah berjalan lancar. Mulai dari perencanaan hingga pelaksanaan . Serta ada kegiatan mengajar di MI Manba'ul ulum 2 ini dilakukan pada siswa kelas IV, V, dan VI dengan Jumlah siswa kelas sebanyak 75 siswa.

Adapun Pelaksanaan Mengajar ini dilakukan dua hari dalam sepekan dengan presentase waktu dilakukan selama 1-2 x 35 menit dan dimulai pada pukul $07.15-11.55$ WIB, ralatif sesuai dengan jadwal masingmasing. Adapun hasil yang dapat disampaikan selama mengajar adalah anakanak sangat senang ketika saya mengajarkan mereka dan anak-anak disini masih sangat pemalu ketika bertemu dengan orang yang baru ia kenal terlebih lagi usia yang masih tergolong anak-anak menambah sedikit kesulitan untuk menerapkan metode mengajar. Dalam penyampaian pembelajaran mahasiswa di tuntut untuk megajar aqidah akhlaq, fiqih, sejarah Kebudayaan Islam, Bahasa Sunda, dan Tematik K2013. Pada pembelajaran mereka sangat bersemangat dan enerjik. pada awalnya untuk meminta mereka mengenalkan diri di depan kelas saja sangat sulit bahkan masih ada yang malu untuk memperkenalkan diri di depan kelas Namun kami terus berusaha mendekatkan diri dengan mereka dengan melakukan berbagai aktivitas di awal pertemuan agar suasana mencair seperti mengadakan games dan tanya jawab sungguh hebat anak-anak sangat pintar-pintar dan bersemangat dalam belajar.

Setelah selesai belajar kami mulai memasuki sesi akhir yaitu evaluasi.

Dalam tahap evaluasi mahasiswa menggunakan macam-macam metode seperti games individu maupun kelompok.

Akhirnya pembelajaran pun selesai. Kemudian saya memberikan sedikit motivasi dan evaluasi bagi semua siswa agar nanya lebih giat lagi dalam mengikuti pelajaran dikelas. Kemudian pembelajaran ditutup dengan salam dan dilanjut dengan bersalam-salaman.

\section{Bidang Kesehatan Masyarakat}

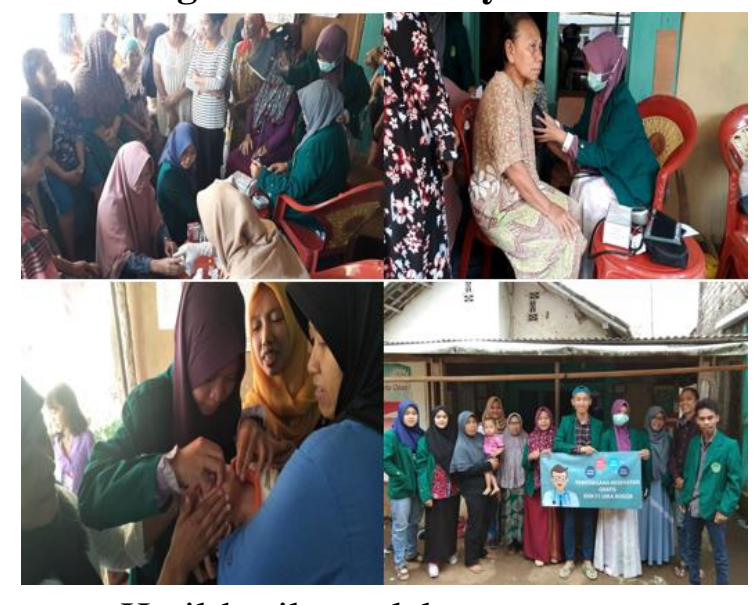

Hasil-hasil pelaksanaan program kuliah kerja nyata (KKN) yang berhasil dilaksanakan dalam bidang kesehatan di 
Kp.Poncol Desa Ciampea Kecamatan Ciampea yaitu berupa pelaksanaan pendampingan program posyandu pemberian Vitamin A untuk bayi dan balita dan cek kesehatan gratis.

Kegiatan kesehatan di Kp.Poncol Desa Ciampea Kecamatan Ciampea berjalan lancar, setiap bulannya khususnya posyandu. Target posyandu adalah untuk bayi dan balita. Posyandu dilaksanakan tanggal 16 di setiap bulannya. Sarana kesehatan yang terdapat di sekitar Kp.Poncol Desa Ciampea Kecamatan Ciampea adalah dari puskesmas ciampea.

Pada hari kamis, tanggal 16 Agustus 2018 telah dilaksanakan program kuliah kerja nyata $(\mathrm{KKN})$ dalam bidang kesehatan berupa pendampingan posyandu. Tempat kegiatan pelaksanaan pendampingan posyandu di balai posyandu Kp.Poncol Desa Ciampea Kecamatan Ciampea. Bentuk kegiatannya adalah pendampingan pelaksanaan kegiatan posyandu dan terlibat dalam kegiatan tersebut. Tujuan dari pelaksanaan pendampingan posyandu yaitu meningkatkan pelayanan kesehatan ibu dan anak, meningkatkan kemampuan masyarakat untuk mengembangkan kesehatan dan kegiatan-kegiatan lain yang menunjang hidup sehat. Sasaran dalam kegiatan pelaksanaan pendampingan posyandu yaitu untuk balita dan ibu yang memiliki anak balita. Peran mahasiswa dalam kegiatan pelaksanaan pendampingan posyandu yaitu ikut membantu kegiatan menimbang berat badan, pengukuran tinggi badan, lingkar kepala untuk balita, ikut membantu memberikan Vitamin A untuk bayi dan dan balita, ikut membantu membagikan makanan, ikut membantu menuliskan data hasil penimbangan dan pengukuran tinggi badan serta lingkar kepala. Peran masyarakat dalam kegiatan pelaksanaan pendampingan posyandu yaitu yang menyelenggara kegiatan, ikut berpartisipasi aktif menghadiri posyandu dengan serangkaian kegiatan seperti penimbangan berat badan, pengukuran tinggi badan, dan lingkar kepala balita. Faktor pendukung dalam kegiatan pelaksanaan pendampingan posyandu yaitu kegiatan ini merupakan kegiatan rutin yang dilaksanakan setiap bulan di tanggal 16 sehingga para warga, khususnya para ibu yang memiliki anak balita dan bayi, mengetahui dengan pasti jam pelaksanaan kegiatan posyandu. Faktor penghambat dalam kegiatan pelaksanaan pendampingan posyandu yaitu terdapat acara dari masing masing pihak masyarakat yang pelaksanaannya bertepatan dengan pelaksanaan posyandu, sehingga ada yang tidak menghadiri kegiatan posyandu. Hasil dari kegiatan pelaksanaan program pendampingan posyandu Kp.Poncol Desa Ciampea Kecamatan Ciampea yaitu kegiatan dilaksanakan di balai Posyandu Kp.Poncol Desa Ciampea Kecamatan Ciampea yang diikuti oleh 25 balita. RataRata anak balita Kp.Poncol berada dalam gizi normal yang diketahui dengan berat badan dan tinggi badan anak yang mayoritas mengalami peningkatan.

Pada hari kamis, tanggal 30 Agustus 2018 telah dilaksanakan program kuliah kerja nyata $(\mathrm{KKN})$ dalam bidang kesehatan berupa cek kesehatan gratis. Tempat kegiatan pelaksanaan cek kesehatan gratis di balai posyandu Kp.Poncol Desa Ciampea Kecamatan Ciampea. Bentuk kegiatannya adalah disediakan sarana cek kesehatan seperti cek berat badan, tinggi badan, tekanan darah, gula darah, dan asam urat dan warga datang memeriksakan kesehatannya. Tujuan dari pelaksanaan kegiatan cek kesehatan gratis yaitu untuk memberikan fasilitas cek kesehatan gratis kepada warga Kp.Poncol Desa Ciampea 
Kecamatan Ciampea sehingga warga mengetahui bagaimana kondisi kesehatannya. Sasaran dalam kegiatan pelaksanaan cek kesehatan gratis yaitu bapak-bapak dan ibu-ibu warga Kp.Poncol Desa Ciampea Kecamatan Ciampea. Peran mahasiswa dalam kegiatan pelaksanaan cek kesehatan gratis yaitu 1 orang mendampingi petugas kesehatan di masing masing pengecekan kesehatan, 1 orang yang bertanggung jawab dalam pengecekan berat badan dan tinggi badan, 1 orang yang bertanggung jawab dalam pengecekan tekanan darah, 1 orang yang bertanggung jawab dalam pengecekan gula darah dan asam urat, 2 orang mengarahkan warga dalam melakukan cek kesehatan gratis, 1 orang mendokumentasikan kegiatan, yang lainnya menyiapkan sarana dan prasarana yang dibutuhkan dalam kegiatan cek kesehatan gratis. Peran masyarakat dalam kegiatan pelaksanaan cek kesehatan gratis yaitu sebagai sasaran kegiatan cek kesehatan gratis. Faktor pendukung dalam kegiatan pelaksanaan cek kesehatan yaitu warga antusias terhadap adanya kegiatan cek kesehatan gratis, adanya kesadaran warga akan pentingnya memeriksakan kesehatannya kepada petugas cek kesehatan. Faktor penghambat dalam kegiatan pelaksanaan cek kesehatan gratis yaitu sebagian warga takut akan hasil cek kesehatan sehingga enggan untuk memeriksakan kesehatannya. Hasil dari kegiatan pelaksanaan cek kesehatan gratis yaitu tercatat sebanyak 72 warga Kp.Poncol Desa Ciampea Kecamatan Ciampea yang terdiri dari bapak-bapak dan ibu-ibu yang memeriksakan kesehatannya berupa pengecekan tinggi badan, berat badan , tekanan darah, gula darah, asam urat, serta konsultasi kesehatan, warga Kp.poncol rata-rata mengalami penyakit asam urat, untuk berat badan dan tinggi badan pada warga Kp.Poncol masih banyak yang mengalami berat badan dan tinggi badan yang belum ideal, untuk tekanan darah pada warga Kp.Poncol masih banyak yang mengalami tekanan darah yang tinggi.

\section{Bidang Lingkungan}

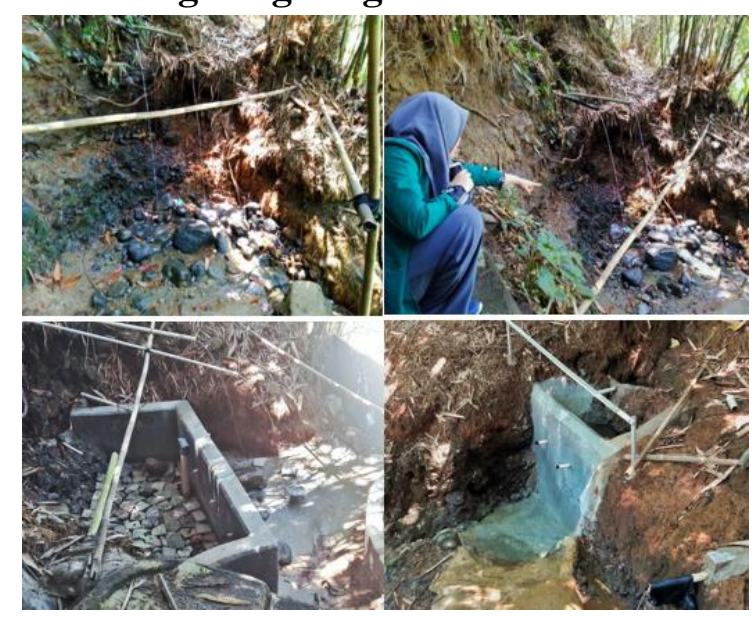

\section{Pancuran air desa poncol.}

Kegiatanpembangunan penampungan air ini, sudah di wacanakan oleh warga sejak hari ke 2 kami datang ke desa tersebut, warga berharap kami (Peserta KKN kelompok 11) membantu baik material maupun tenaga, agar rencana pembangunan penampungan air ini terralisasikan dengan baik dan lancar.

Setelah mendapat bantuan dana dari kelurahan setempat, dan kesediaan warga untuk membantu tenaga, material serta tenaga, maka pada hari senin 27 agustus 2018, proses pembangunan nya di mulai.

Waktu pelaksanaan nya sendiri, di lakukan setiap hari sejak Rabu, 22 agustus 2018 sampai dengan 25 Agustus 2018, dimulai pukul 08:00 pagi sampai 11:00 kemudian istirahat, di mulai kembali pukul 13:00 sampai 15:00 kemudian isoma, dan terakhir pukul 16:00 sampai dengan 17:00 dan kegiatan selesai.

Hingga tanggal 3 September terakhir kami lihat pembangunan penampungan sudah hampir selesai, sehubungan dana yang terbatas kemungkinan pembangunan tersebut di lakukan kemudian waktu, tidak 
dapat di selesaikan hingga benar benar selesai saat itu, berhubung waktu KKN kami terbatas, kami tidak bisa membantu sampai beres.

\section{Bidang Ekonomi}

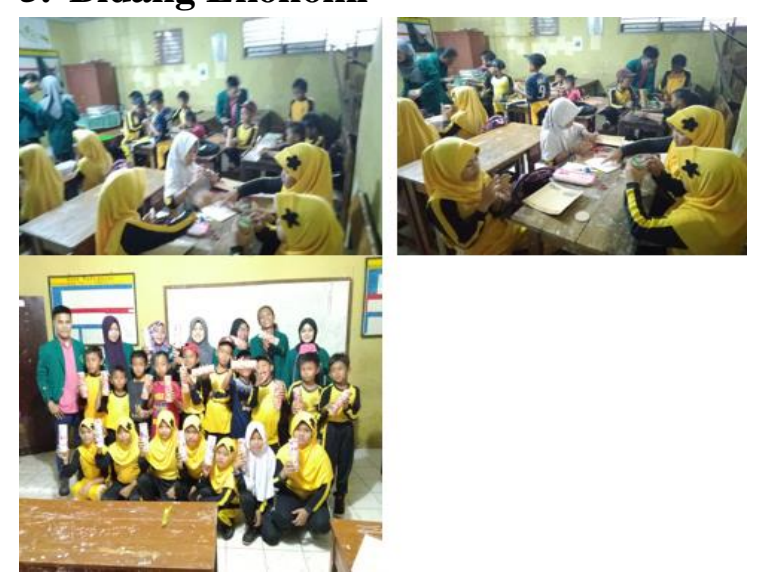

\section{Laporan kegiatan pembuatan celengan}

Dalam kegiatan pembuatan celengan di Manba'ul ulum 2 kp.poncol kecamatan ciampea sudah berjalan lancar. Mulai dari perencanaan hingga pelaksanaan. Serta kegiatan pembuatan celengan di MI Manba'ul ulum 2 ini dilakukan pada siswa kelas V Jumlah siswa kelas V sebanyak 23 siswa.

adapun Pelaksanaan pembuatan celengan ini dilakukan dalam satu hari yaitu pada hari sabtu tanggal 1 September 2018 dilakukan selama $2 \times 35$ menit dan dimulai pada pukul 08.00 - 09.10 WIB. Bahan bahan yang kami pakai dalam kegiatan ini, antara lain : kardus bekas, lem fox, solatip, gunting, kater, pinsil, dan kertas kado. Adapun hasil yang dapat disampaikan selama pelaksanaan adalah anak-anak sangat senang ketika kami mengajarkan mereka dan anak-anak disini sangat antusias dengan kegiatan pembuatan celengan ini, ketika kegiatan sedang berlangsung kami sedikit di buat kualahan dengan sikap antusias mereka. Pada kegiatan ini selain mengajarkan membuat celengan dari bahan bekas, kami juga tidak lupa mengingatkan mereka agar rajin menabung. Selain menghindarkan mereka dari menghamburkan uang jajan, menabung juga dapat membentuk mereka agar hidup hemat dan dengan hasil tabungan yang mereka kumpulkan dapat mereka gunakan untuk berbagai keperluan mereka seperti membeli buku pelajaran, seragam skolah, atau keperluan lain.
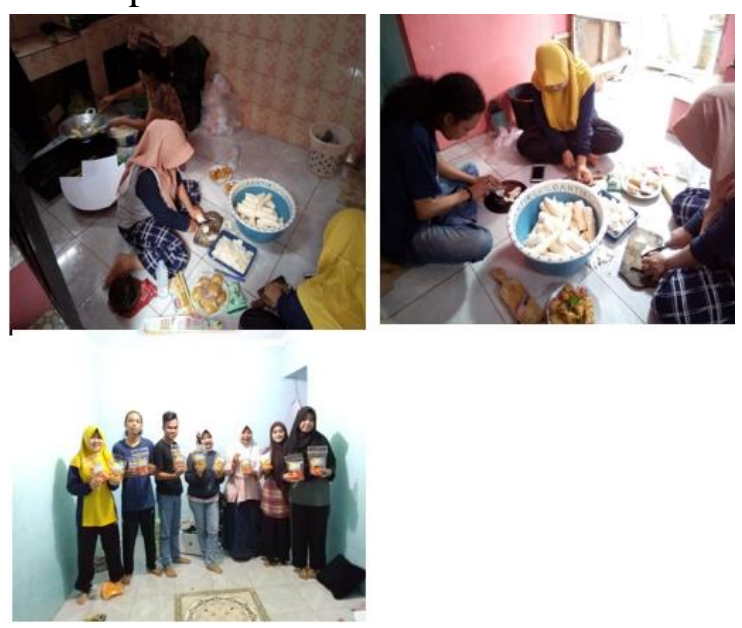

\section{Laporan pembuatan keripik singkong}

Setelah survei dan melakukan penyuluhan selama kurang lebih 1 minggu kami mendapatin pontensi di kp. Poncol, yaitu kebun singkong yang luas dan beberapa warga setempat yang gemar membuat olahan dari singkong yang mereka sebut enye-enye dan ringgining. Pada hari jum'at tanggal 31 Agustus 2018 kami di bantu beberapa warga melaksanakan kegiatan pembuatan keripik singkong yang sebelumnya sudah kami rencanakan akan membuatkan kemasan serta nama atau brand agar keripik singkong yang kami buat dapat masuk ke pasar atau toko online dan agar keripik singkok ini juga dapat menjadi usaha rumahan bagi warga setempat karena mayoritas pekerjaan warga setempat adalah petani singkong.

Bahan bahan dalam pembuatan ini antaralain : singkong, garam, minyak goreng, bumbu perasa

Cara pembuatan : kupas kulit singkong lalu rendam dengan air, iris singkong tipis tipis, kemudian panaskan minyak goreng, siapkan air garam, lalu 
goreng singkong yang sudah kita iris dan masukan secukupnya air garam yang sudah kita siapkan tadi. Tiriskan singkong yang sudah mulai kecoklatan. Dinginkan singkong lalu masukan singkong ke dalam toples bersama dengan bumbu perasa, kemudian aduk hingga merata, lalu

\section{KESIMPULAN}

Tujuan program: (1) Mendorong program pengabdian pada masyarakat yang dilakukan oleh mahasiswa dalam rangka mewujudkan program dari Universitas Ibn Khaldun Bogor sesuai dengan Visi dan Misi Universitas Ibn Khaldun Bogor. (2) terciptanya saling belajar antara mahasiswa dengan masyarakat sehingga tumbuh nilainilai dasar yang menyangkut pemahaman dan penghayatan kondisi riil masyarakat. (3) menumbuhkan rasa simpati masyarakat terhadap civitas akademik Universitas Ibn

\section{REFERENSI}

Administrasi Profil Desa Ciampea

Fahmi eroby, 2008, Pendidikan berbasis masyarakat. Yogyakarta

LPPM; Universitas Ibn Khaldun Bogor;. (2018). Petunjuk Pelaksanaan KKN Tematik Terintegrasi 2018. masukan ke dalam kemasan yang sudah di sediakan.

Keripik singkong yang kita buat, kita pasarkan dengan harga jual Rp.5000/ 1pcs. Dengan harga Rp.5000 dirasa sangat terjangkau untuk kalangan warga $\mathrm{kp}$. Poncol.

Khaldun Bogor dengan mengajak masyarakat untuk mengembangkan potensi keluargan dan meningkatkan kesadaran masyarakat dalam pembangunan.

Dampak bagi masyarakat, msayarakat bisa terbantu dengan adanya tampungan air sehingga tidak perlu antri untuk bisa mengambil air di mata air tersebut, dan juga msayarakat sekitar bisa lebih aktif dalam keagamaan dengan di bentuknya ramaja Mesjid.

https://id.m.wikipedia.org/wiki/Ciampea, Ciampea,_Bogor

https://sh0likhin.wordpress.com/2010/03/2 4/definisi-pemuda/ 